\title{
Genomics in Modern Medicine: Preparing the Future Healthcare Providers
}

\author{
Bojana Stevich-Heemer ${ }^{1}$ and Alice Hudder ${ }^{2 *}$ \\ ${ }^{1}$ LECOM School of Pharmacy, 1858 W. Grandview Blvd. Erie, Pennsylvania, USA \\ ${ }^{2}$ Division of Biochemistry and Medical Genetics, Lake Erie College of Osteopathic Medicine 1858 W. Grandview Blvd, Erie, Pennsylvania, USA
}

\begin{abstract}
Received: April 15, 2016; Accepted: May 12, 2016; Published: May 15, 2016
*Corresponding author: Alice Hudder, Division of Biochemistry and Medical Genetics, Lake Erie College of Osteopathic Medicine, 1858 W. Grandview Blvd. Erie, Pennsylvania, USA 16509, Tel: +814-866-8158; Fax: +814-866-8411; E-mail: ahudder@lecom.edu
\end{abstract}

\begin{abstract}
While there is agreement in the medical community that the incorporation of genomic information into patient care has great potential for improved outcomes, there is still much controversy about how genomics will be applied, and importantly, how physicians and other healthcare providers will be trained to utilize this information. This presents a serious challenge in medical education. The following is a mini-review on the genomic readiness of pharmacists and physicians and the way that medical education is changing to meet this need. We propose that there is a need for more educational programs in the pharmacy and medical school curricula for covering genomics. Different types of activities should be developed in these curricula to help young practitioners become proficient in genomics. Pharmacy schools report more coverage of genomics and especially pharmacogenomics in their curricula than medical schools. It is also important to note that other professional health care curricula (e.g. nursing) will also need to determine the level of these healthcare practitioners readiness to perform their duties and the need for their education in the area of genomics and pharmacogenomics. This could be an opportunity for greater Inter professional Education. We conclude that more educational programs are needed in order to make the promise of precision medicine a reality.
\end{abstract}

Keywords: Genomics; Precision medicine; Medical education; Pharmacogenomics; Pharmacy education; Inter professional education

\section{Introduction}

"The potential for precision medicine to improve care and speed the development of new treatments has only just begun to be tapped." (FACT SHEET: President Obama's Precision Medicine Initiative, 2015).

In January 2015, President Obama announced the Precision Medicine Initiative for the United States to improve healthcare. This ambitious plan includes funding for a large cohort study to facilitate interpretation of genomic variants and encourage data sharing, funding for identifying genomic drivers in cancer and targeted cancer treatments, the development of a curated database, and the development of technology to help protect privacy. While this plan is designed to increase the use of genomic technology, it fails to address the need for education aimed at implementation of genomics at the clinical level.

\section{The Age of Precision Medicine}

With the advent of the Human Genome Project came the promise of personalized medicine [1-3]. Personalized or precision medicine refers to using information about a patient's genetic makeup to tailor strategies for the detection, treatment, or prevention of disease. Initially this was too costly and timeconsuming for practical application. But recent advances in technology are turning this idea into reality. For example, Next Generation Sequencing (NGS) analysis, which has recently received FDA approval [4], is being utilized to provide both whole genome and whole exome sequence analysis, to generate comprehensive data on individual patient DNA. This technology provides fast turnaround time at an affordable price-one which health insurance providers are willing to cover [5], thus facilitating the use of genomic information in patient care. This new capability in medicine has led to many questions. How will we integrate genomic information into clinical practice? How will we protect patient privacy? What are the most relevant applications of genomics in medicine? Are physicians and other healthcare workers knowledgeable about genomics and its applications? And, critically, how will we train current and future physicians and healthcare professionals to implement this information into clinical practice?

\section{Current State of Genetics Education for Physicians}

Since the completion of the Human Genome Project, there is a growing recognition worldwide of the importance of genetics education for physicians [6-8] As a result, there have been studies on how and when genetics is taught in the medical curriculum $[9,10]$. Most medical schools in Canada and the United States were shown to devote an average of 36 hours (with a range of 18-102 hours) of teaching to medical genetics with the most commonly taught topics being cancer genetics, Mendelian disorders, cancer genetics, multi factorial inheritance, clinical cytogenetic, and patterns of inheritance[10]. These lectures are usually delivered in the first year or two of preclinical medical training and this curriculum has not changed much in the last decade. Assessment of competency in medical practitioners has 
revealed a low level of competency in genetics and application of genomics relevant to their medical practices $[11,8]$. In one study, physicians in family practice felt inadequately prepared to utilize genetic information even though they felt it was important to do so [11]. In Australia, general practitioners felt underprepared to use genetic testing in diagnostics or to counsel patients who had undergone genetic testing [8]. More recently, a survey of medical internists revealed a wide variation of the utilization of genetic information by disease, but a general lack of preparation or even unwillingness to use genomic data in patient care [12]. And although $65 \%$ of respondents reported having counseled patients on genetic issues, they rated their knowledge of genetics and guidelines for genetic testing as generally poor $(79 \%$ and $82 \%$, respectively).

\section{Applications and Challenges of Genomics in Medicine}

One area of concern for patients is how genomic information is being utilized outside the clinical applications and the potential for harm. In 2008, the U.S. Congress passed the Genetic Information Nondiscrimination Act (GINA) to protect patients from discrimination by employers or health insurers based on their genotype [13]. The anticipation was that health insurance companies may deny coverage based on the finding of specific mutations, for example those in the BRCA gene that are predictive of breast cancer. Or life insurance companies may want to raise premiums or deny coverage for individuals with genetic predispositions to certain diseases. Despite the protections set forth by this law, there may still be lingering fear among patients about obtaining genomic testing.

One of the big questions being asked is concerning the clinical utility of the data provided by genomic sequencing $[14,15]$. Each variant discovered must be assessed for positive predictive value across the population in order to be applied to the risk assessment of complex diseases. Many variants are being discovered with unknown significance. In addition, there is the likelihood of the discovery of incidental findings, not related to the patient's primary complaint. These must be interpreted and handled by the physician according to medical ethics guidelines [16]. There is a need for large cohort studies with genome sequences to sort out the huge amount of genomic information being generated to improve clinical utility. The President's new Precision Medicine Initiative will help target this important aspect of genomic implementation.

While the clinical applications of genomics is still an active area of research, with much left yet to be discovered, there have been significant gains in our understanding of a great number of genetic variants with biological implications and clinical utility[17-19]. Currently one of the best and most clinically useful applications of genomics in medicine is in pharmacogenomics [20]. Many gene variants have been identified that are predictive of a patient's response to certain medications which can inform both the choice of medication as well as dosing. Some examples of drugs that require genetic testing prior to prescribing include Carbamazapine, Ivacaftor, Tetrabenazine, Valproic Acid and Pimozide, while for others, such as Clopidogrel, Warfarin, and
Abacavir, genetic testing is recommended to avoid adverse reactions[21].And yet relatively few physicians in the United States have implemented the use of genomics in patient treatment plans. In a nationwide survey, greater than $97 \%$ of physicians thought that genetic variations may influence drug response in their patients, but nearly $90 \%$ felt inadequately prepared to utilize pharmacogenomic data [22].

Another area where genomics is being applied with increasing success is in cancer diagnosis and treatment [23]. Tumor markers are defined as biochemical markers which are expressed by tumor cells [24] and are often detectable in a patient's serum. Prostate Specific Antigen (PSA) is used to help diagnose patients with prostate cancer and to monitor the effectiveness of treatment of patients with prostate cancer [25]. One of the first oncology drugs approved by the Food and Drug Administration whose response depends on the patient's genetic makeup is trastuzumab. Trastuzumab was originally approved for the treatment of breast cancer. This medication, which is a humanized monoclonal antibody, is only effective in patients whose tumors express the Her2 receptor [26]. Therefore it is necessary to do genetic testing of a patient's breast cancer cells before using this medication. Another oncology medication that also needs genetic testing before the administration is imatininb, a tyrosine kinase inhibitor. This medication is utilized in patients with Chronic Myelogenous Leukemia (CML). CML is a clonal hematopoietic stem cell disorder which results from a reciprocal translocation between chromosomes 9 and $22 \mathrm{t}(9 ; 22)$. This translocation results in the fusion of two genes, BCR and ABL, which is translated into Bcr-Abl1 fusion protein. Imatinib, a first targeted agent against the Bcr-Abl1 fusion protein revolutionized treatment of patients with CML [27]. Many other oncology drug used to the treatment of different types of cancer utilize genetics for optimal dosing. Some of these medications include Cetuximab (28) and Irinotecan (28).

\section{Pharmacogenomics Education}

Since pharmacogenomics is becoming an integral part of patient care and management there is a need to educate different healthcare professionals involved in patient care how to perform and utilize pharmacogenetics testing. Recent survey research looked at how pharmacists perceived themselves in readiness to apply pharmacogenomics in clinical practice. One of those surveys done by McCullough et al. showed that pharmacists perceived themselves as lacking in confidence and educational background in pharmacogenomics [28]. Other surveys showed similar data. In 2002, the American Association of Colleges of Pharmacy Academic Affairs Committee proposed core competencies in pharmacogenetics and pharmacogenomics. These core competencies are divided into three major groups: 1) genetic basis of diseases, 2) drug discovery and 3) ethical, social and economic applications. The Accreditation Council for Pharmacy Education Accreditation Standards and Guidelines also recommend that basis in pharmacogenetic and pharmacogenomics should include the following topics: genetic basis for disease, drug action, drug metabolism and individual drug dosing [29]. Murphy et al. (2010), performed survey research from 2008 to 2009 to assess what 
percentage of pharmacy schools includes pharmacogenomics in their curricula. They reported that $89.3 \%$ of participants include pharmacogenomics in their curricula compared to 39\% reported by Latif and McKay in 2005. So there has been a substantial increase in teaching pharmacogenetics and pharmacogenomic topics in pharmacy schools curricula over the last decade and most of US colleges of pharmacy include pharmacogenetic topic on their curricula but the depth of coverage of these topics among pharmacy school curricula may be still inadequate [30].

Similar to what is being done with pharmacist education, physician education in the area of genomics is in need of a transformation. Physicians of all specialties must be taught how to make sense of this rapidly accruing body of information [31]. At the national level, several groups have been working on the issues involved in implementation of genomics in medicine, such as the Association of Professors of Human and Medical Genetics (APHMG), the National Coalition for Health Professional Education in Genetics (NCHPEG), and the InterSociety Coordinating Committee for Physician Education in Genomics (ISCC). Guidelines have been developed for genomics education based on the framework of the Accreditation Council for Graduate Medical Education (ACGME) and American Board of Medical Specialties (ABMS) core competencies that address the knowledge, skills, and attitudes expected of physicians [32,33]. The resulting guidelines are a great start to guide genetics education at both the level of undergraduate and graduate medical training for physicians.

Genomics in medicine has great potential for improving healthcare through better diagnostics and customized treatment plans for individuals, making this an exciting time to be part of the healthcare system. In order to turn the promise of precision medicine into reality and implement genomics into everyday clinical applications, additional education programs are needed for all health care workers. When developing educational programs in genomics and pharmacogenetics it is important that these programs are targeted to the specific audience. Application of genomics and pharmacogenomics depends on readiness of many different healthcare professionals including: pharmacists, geneticists, nurses and many others. Understanding the basic concepts of genomics and pharmacogenetics is important for all these professionals; however each profession has specific areas that are more important for that particular profession so these educational programs should contain specific information relevant to their practice. Also, when developing these educational programs one should make sure that these programs are not available just as live programs but also be offered as webinars, recorded video programs and written programs so there are different ways that a busy healthcare professional can access these programs [34-36].

\section{References}

1. Wylie Burke, Bruce M Psaty, Personalized Medicine in the Era of Genomics, JAMA. 2007;298 (14):1682-1684. doi:10.1001/ jama.298.14.1682.

2. Jeanette McCarthy. Welcome to the Future of Medicine, Genome. 2014:10-12.
3. D McMullan, What is Personalized Medicine?, Genome. 2014:32-39.

4. Francis S Collins, Margaret A Hamburg. First FDA Authorization for Next-Generation Sequencer. N Engl J Med. 2013; 369:2369-2371. doi: 10.1056/NEJMp1314561

5. Kevin Davies. Cheaper, Better, Faster, Stonger. Genome. 2014:18-19.

6. Jean Jenkins, Miriam Blitzer, Karina Boehm, Suzanne Feetham, Elizabeth Gettig, Ann Johnson, et al. Recommendations of core competencies in genetics essential for all health professionals. Genetic Medicine. 2001;3:155-159.

7. Kirklin D, Responding to the implications of the genetics revolution for the education and training of doctors: a medical humainites approach. Med Educ. 2003;37(2):168-173.

8. Metcalfe S, Hurworth R, Newstead J, Robins R. Metcalfe, R Hurworth, J. Newstead, R. Robins. Needs assessment study of genetics education for general practitioners in Australia. Genetics in Medicine. 2002;4(2):7177.

9. Thurston VC, Wales PS, Bell MA, Torbeck L, Brokaw JJ. The current status of medical genetics instruction in the U.S. and Canadian medical schools. Acad Med. 2007;82(5):441-445.

10. Plunkett-Rondeau J, Hyland K, Dasgupta S. Training future physicians in the era of genomic medicine: trends in undergraduate medical genetics and education. Genet Med. 2015;17(11):927-934. doi: 10.1038/gim.2014.208. Epub 2015 Feb 12

11. Burke S, Stone A, Bedward J, Thomas H, Farndon P. A "neglected part of the curriculum" or "of limited use"? View on genetics training by nongenetics medical trainees and implications for delivery, Genet Med. 2006;8(2):109-115.

12. Klitzman R, Chung W, Marder K, Shanmugham A, Chin LJ, Stark M, et al. Attitudes and Practices Among Internists Concerning Genetic Testing, J Genet Couns. 2013; 22(1):90-100. doi: 10.1007/s10897012-9504-z

13. Kathy L Hudson, Holohan MK, Collins FS. Keeping Pace with the Times - The Genetic Information Nondiscrimination Act of 2008. N Engl J Med. 2008;358:2661-2663. doi: 10.1056/NEJMp0803964.

14. Manolio TA, Genomewide association studies and the assessment of the risk of disease, N Engl J Med. 2010; 363:166-176. doi: 10.1056/ NEJMra0905980.

15. Caskey CT, Using Genetic Diagnosis to Determine Individual Therapeutic Utility, Annual Review of Medicine. 2010;61:1-15. doi: 10.1146/annurev-med-011209-132719.

16.SM Wolf, FP Lawrenz, CA Nelson, JP Kahn, MK Cho, EW Clayton, et al.Mangaing incidental findings in human subjects research: analysis and recommendations, J Law Med Ethics. 2008;36(2):219-248,211. doi: 10.1111/j.1748-720X.2008.00266.x.

17. Biesecker LG, Green RC. Diagnostic Clinical Genome and Exome Sequencing. N Engl J Med. 2014;370(25):2418-25. doi: 10.1056/ NEJMra1312543.

18. Burke W, Laberge AM, Press N. Debating Clinical Utility, Public Health Genomics. 2010;13:215-223. doi:10.1159/000279623.

19.E. G. Phimister, Curating the Way to Better Determinants of Genetic Risk. N Engl J Med. 2015;372:2227-2228. doi: 10.1056/ NEJMe1506276.

20. MV Relling, JM Hoffman, Should pharmacogenomic studies be required for new drug approval?, Clinical Pharmacology \& Therapeutics Personalized Medicine. 2007;81(3);425-428. doi: 10.1038/ 
sj.clpt.6100097.

21. Whirl-Carrillo M, McDonagh EM, Hebert JM, Gong L, Sangkuhl K, Thorn $\mathrm{CF}$, et.al. Pharmacogenomics knowledge for personalized medicine, Clin Pharmacol Ther. 2012;92(4):414-417. doi: 10.1038/clpt.2012.96.

22. Stanek EJ, Sanders CL, Taber KA, Khalid M, Patel A, Verbrugge RR, et al. Adoption of pharmacogenomic testing by US physicians: results of a nationwide survey, Clin Pharmacol Ther. 2012;91(3):450-458. doi: 10.1038/clpt.2011.306.

23. Vogelstein B, Papadopoulos N, Velculescu VE, Zhou S, Diaz LA Jr, Kinzler KW. Cancer genome landscapes. Science. 2013;339(6127):15461558. doi: 10.1126/science.1235122.

24.Virji MA, Mercer DW, Herberman RB. Tumor Markers in Cancer Diagnosis and Prognosis, CA-A Cancer Journal for Clinicians. 2008;38(2):104-126.

25. Cuzick J, Thorat MA, Andriole G, Brawley OW, Brown PH, Culig Z, et.al. Prevenion and Early Detection of Prostate cancer, Lancet Oncology, 2014;15(11):484-492.

26. McKeage K, Perry CM. Trastuzumab: a review of its use in the treatment of metastatic breast cancer overexpressing HER2. Drugs. 2002;62(1):209-243.

27.J Apperley, Chronic Myeloid Leukemia, The Lancet, 2015;385(9976):1447-1459. doi: 10.1016/S0140-6736(13)62120-0.

28. McCullough KB, Formea CM, Berg KD, Burzynski JA, Cunningham $\mathrm{JL}, \mathrm{Ou} \mathrm{NN}$, et al. Assessment of the pharmacogenomics educational needs of pharmacists, Am J Pharm Edu 2011;75(3):51.

29. Kelly C. Lee, Joseph D. Ma, Karen Suchanek Hudman, Grace M. Kuo. A Train-the-Trainer Approach to a Shared Pharmacogenomics
Curriculum for US Colleges and Schools of Pharmacy, Am J Pharm Educ. 2012;76(10): 193. doi:10.5688/ajpe7610193

30. Murphy JE, Green JS, Adams LA, Squire RB, Kuo GM, McKay A. Pharmacogenomics in the Curricula of Colleges and Schools of Pharmacy in the United States, Am J Pharm Educ. 2010;74(1):7.

31. Jameson JL, Longo DL., Precision Medicine - Personalized, Problematic, and Promising, N Engl J Med. 2015;372(23):2229-2234. doi: 10.1056/ NEJMsb1503104.

32. K. M. Hyland, S. Dasgupta, K. Garber, J.-A. Gold, H. Toriello, K. Weissbecker and D. Waggoner, APHMG Genetics Competencies Working Group,APHMG Council, 2013.

33. Korf BR, Berry AB, Limson M, Marian AJ, Murray MF, O’Rourke PP, et al. Framework for development of physician competencies in genomic medicine: report of the Competencies Working Group of the InterSociety Coordianting Committee for Physician Education in Genomics. Genet Med. 2014;16(11):804-9. doi: 10.1038/gim.2014.35.

34. Hoffman JM, Haider CE, Wilkinson MR, Crews KR, Baker BDK, Relling MV, et al. PG4KDS: A Model for the Clinical Implementation of Pre-emptive Pharmacogenetics. Am J Med Genet C Semin Med Genet. 2014;166C(1):45-55. doi: 10.1002/ajmg.c.31391.

35.Scott SA, Personalizing Medicine with Pharmacogenetics, Genet Med. 2011;13(12):987-995. doi: 10.1097/GIM.0b013e318238b38c.

36. Shuldiner AR, Relling MV, Peterson JF, Hicks JK, Sadee W, Klein TE, et al. The Pharmacogenomics Research Network Translational Pharmacogenetics Program: Overcoming Challenges of Real-World Implementation. Clin Pharmacol Ther. 2013;94(2):207-210. doi: 10.1038/clpt.2013.59. 